\title{
CUESTIONES DE ORDEN: SEMÁNTICA Y SINTAXIS DE LOS ADJETIVOS ORDINALES ${ }^{1}$
}

\author{
Luis Eguren y Antonio Fábregas \\ Universidad Autónoma de Madrid \\ luis.eguren@uam.es y webfabregas@gmail.com
}

\begin{abstract}
Resumen
En este trabajo mostramos que los adjetivos ordinales del español tienen distintas propiedades semánticas y sintácticas en posición pre y postnominal. Estos modificadores son auténticos adjetivos ordinales (esto es, convierten un conjunto en una serie ordenada) $\tan$ solo cuando preceden al nombre; cuando lo siguen, sin embargo, simplemente asignan un número a una entidad, sin ordenar necesariamente una serie. Proponemos, en concreto, que los ordinales postnominales son adjetivos relacionales clasificadores que establecen una relación entre un nombre y un número, mientras que los ordinales prenominales se comportan como los adjetivos situacionales del tipo de próximo, siguiente, anterior o posterior, que denotan relaciones de secuenciación espacio-temporal entre entidades. Estudiamos también las propiedades idiosincrásicas de los ordinales primero y último, unas propiedades que se derivan en última instancia del hecho de que estos ordinales abren o cierran una serie.

PALABRAS CLAVE: ordinales, adjetivos, orden de palabras, sintagma nominal, interfaz sintaxis-semántica.
\end{abstract}

\begin{abstract}
In this article we show that Spanish ordinal adjectives in pre- and postnominal position have different semantic and syntactic properties. We notice that these modifiers are proper ordinal adjectives -that is, adjectives that turn a set of entities of the same class into a series- only when they appear before the noun; when ordinal adjectives follow the noun in Spanish, however, they just assign a number to a certain entity, without necessarily ordering any set. We argue, more specifically, that postnominal ordinals are classifying relational adjectives that establish a relation between a noun and a number, while prenominal ordinals behave like a subtype of situational adjectives, such as próximo 'next' siguiente, 'following', anterior 'previous' or pasado 'last', which denote spatiotemporal sequencing relations amongst entities. We also point out that primero, 'first', and illimo, 'last', have some particular properties that ultimately derive from the fact that these ordinal adjectives open and close a series
\end{abstract}

KEY WORDS: ordinals, adjectives, word order, noun phrase, syntax-semantics interface.

\section{Introducción}

Los adjetivos ordinales indican la posición que ocupa la entidad denotada por el nombre al que modifican dentro de una serie de entidades dispuestas sucesivamente en conformidad

1 Este trabajo, que ha sido parcialmente financiado gracias a la subvención al proyecto BFF 2003-06053, es una versión corregida y ampliada de la comunicación que, con el título "El orden de los ordinales", presentamos en el XXXV Congreso de Ia SEL. La investigación de A. Fábregas se ha beneficiado también de la financiación asociada a la beca FPU AP2001-0299 del MECD. Olga Fernández Soriano, Manuel Leonetti, José Portolés y Cristina Sánchez han tenido la amabilidad de leer este texto y nos han ayudado a mejorarlo con sus comentarios. 
con un determinado criterio, que puede permanecer implícito o puede hacerse explícito ${ }^{2}$. Los adjetivos ordinales convierten, por tanto, un conjunto de entidades de la misma clase en una serie ordenada ${ }^{3}$. Como han señalado distintos autores (cfr., v.g., Schnedecker, 2000, 2001), de la caracterización de estos adjetivos como ordenadores se siguen algunas de sus propiedades más importantes. Solo es posible, en primer lugar, ordenar entidades discretas, delimitadas. O dicho de otro modo, solo se pueden ordenar las entidades que se pueden contar. Los nombres de materia, que carecen de límites, del mismo modo que no se pueden contar tampoco se pueden ordenar. Como se observa en (1), los adjetivos ordinales se combinan, en consecuencia, con nombres discontinuos o contables (cfr. $(1 \mathrm{a}, \mathrm{b})$ ) y, cuando aparecen con un sustantivo continuo o no contable, este se recategoriza como discontinuo y o bien se interpreta como una entidad discreta o recibe una interpretación de tipo (cfr. (lc,d)):
(1) a. el segundo capitulo (que he leido)
b. la tercera pregunta (que le han hecho)
c. el segundo café (que he tomado)
d. el tercer vino (que he probado)

Otro rasgo de los adjetivos ordinales que se deriva del hecho de que conviertan un conjunto de entidades de la misma clase en una serie ordenada es su naturaleza inherentemente relacional. Dado que solo puede definirse un orden dentro de un conjunto de elementos con respecto al resto de los elementos del conjunto, los adjetivos ordinales expresan, semánticamente, relaciones: el primer $\mathrm{N}$ es, así, el que precede al resto de los miembros del conjunto ordenado, el último es el que sigue a todos los demás, el segundo es el que sucede al primero, etc. Los adjetivos ordinales no adscriben, por tanto, una propiedad al sustantivo al que modifican, no restringen su extensión, como hacen los adjetivos calificativos, sino que lo identifican dentro de una serie y denotan necesariamente una relación entre dos términos. Así se explica que no puedan aparecer como atributo en una oración copulativa caracterizadora:
(2)
a. Este capitulo es $\left\{{ }^{*}\right.$ primero/aburrido\}.
b. Esa pregunta es \{*'segunda/interesante\}.

Los adjetivos ordinales, por último, para poder asignar a los miembros de un conjunto de entidades de la misma clase un lugar dentro de una serie, deben llevar antes a cabo una operación de partición en dicho conjunto, esto es, deben seleccionar o extraer los elementos

2 En estas páginas solo estudiaremos las propiedades de los adjetivos ordinales. No nos ocuparemos, por tanto, del uso de los numerales ordinales como pronombres o como marcadores del discurso. Los ordinales, en combinación con el artículo determinado (el primero...el segundo...), pueden funcionar como pronombres anafóricos y denotar el orden de aparición de sus antecedentes en el texto (cfr. Schnedecker, 2000). En su empleo como marcadores del discurso (primero...,segundo...; en primer lugar/primeramente....en segundo lugar...), los ordinales son estructuradores de la información que "indican el lugar que ocupa un miembro del discurso en el conjunto de una secuencia discursiva ordenada por partes" (cfr. Portolés, 1998 y Martín Zorraquino y Portolés Lázaro, 1999).

3 En sentido estricto, esta afirmación es cierta solo en el caso de los ordinales prenominales. Como veremos en el apartado $\$ 2, \operatorname{los}$ ordinales postnominales, que equivalen a numerales cardinales, no ordenan intrínsecamente una serie, aunque puedan hacerlo de manera derivada dado que los números están ellos mismos ordenados en una serie. Debe tenerse en cuenta, por otro lado, que los ordinales ordenan tanto "series horizontales" de naturaleza temporal o espacial como "series verticales", esto es, rangos o jerarquías (cfr. \$4). 
que conforman el conjunto de referencia. De ahí que puedan ser, precedidos por el artículo definido, la cabeza de una construcción partitiva ${ }^{4}$ :

\section{(3) a. el primero de los tres capitulos del libro \\ b. la segunda de esas cuatro preguntas}

No existen, por lo que se nos alcanza, estudios detallados de las propiedades "sintácticas" de los adjetivos ordinales del español. Las gramáticas de nuestra lengua suelen tratar los ordinales junto con los numerales cardinales, y en ellas se rastrea su evolución histórica, se describen sus propiedades morfológicas, se constata su alternancia en ciertos contextos con los cardinales y se destaca a veces su naturaleza puramente adjetival, no cuantificativa 5 . Es frecuente encontrar también en estos mismos textos la afirmación de que los adjetivos ordinales se sitúan delante o detrás del nombre al que modifican:

\section{(4) a. el segundo capitulo / el capitulo segundo \\ b. la cuarta fila / la fila cuarta}

No se hace mención alguna, sin embargo, al hecho de que los adjetivos ordinales prenominales y postnominales tienen una semántica y una sintaxis claramente diferenciadas. Una prueba de que los adjetivos ordinales no son del mismo tipo cuando preceden al núcleo nominal y cuando lo siguen es que sintagmas nominales como los de (5), en los que aparece un ordinal delante del nombre y otro detrás, son perfectamente posibles en español:

\section{(5) a. el primer capitulo primero (que leo) \\ b. el segundo piso segundo (que visitamos)}

Como puede verse en (6), los ordinales postnominales seleccionan, además, los sustantivos discontinuos con los que se combinan; los ordinales prenominales, en cambio, no imponen tales rasgos de selección y modifican a cualquier nombre contable ${ }^{6}$ :

\section{(6) a. el capitulo segundo / el segundo capitulo \\ b. la fila cuarta / la cuarta fila}

4 Como es sabido, la cabeza de una construcción partitiva está ocupada canónicamente por determinantes indefinidos: \{dos/algunos/*estos/*todos\} de mis alumnos. Esto es así porque solo los determinantes indefinidos tienen referencia excluyente, es decir, efectúan una partición en la clase denotada por el nombre con el que se combinan de modo que hay siempre miembros de la clase en cuestión que no se tienen en cuenta. La secuencia <artículo determinado+ordinal > es definida, como muestra el hecho de que no aparezca en contextos presentacionales (Hay $\left\{u n /{ }^{*}\right.$ el segundo\} libro en el estante), pero puede ser la cabeza de una construcción partitiva, como se dice en el texto, ya que, al igual que los indefinidos, efectúa una partición en el conjunto cuyos miembros ordena. Dicha secuencia se comporta, a este respecto, como otras expresiones, que aun siendo definidas, también pueden encabezar una construcción partitiva: \{cada uno, la mayoria, la mitad, la tercera parte\} de mis alumnos.

El carácter partitivo de los adjetivos ordinales también explica que en español coloquial haya una marcada tendencia a expresar el ordinal mediante formas que contienen el sufjo partitivo -avo, como en veinteavo por vigésimo, treintaavo por trigésimo, etc.

5 Véase, v.g., Alarcos (1994), Alcina y Blecua (1975), Bello (1847), Fernández Ramírez (1951), Marcos Marín (1999), RAE (1973).

6 Nótese que las secuencias mi hijo tercero y la idea quinta de (6c) y (6d) no son agramaticales (de ahí que no estén marcadas con un asterisco), ya que podríamos encontrar contextos pragmáticamente adecuados en los que los hijos o las ideas fuesen numerados, como habitualmente lo son los capítulos o las filas (cfr. \$2.1.). 


\section{c. \#mi hijo tercero / mi tercer hijo \\ d. \#la idea quinta / la quinta idea}

Otra prueba de que los adjetivos ordinales no funcionan de igual modo cuando preceden y cuando siguen al nombre la encontramos en contrastes como los de (7), donde se observa que podemos tener dos adjetivos ordinales en posición prenominal, pero no así en posición postnominal:

\section{(7) a. el primer segundo portal \\ b. *el portal segundo primero}

En este trabajo daremos cuenta de paradigmas de datos como los de (5), (6) y (7), esto es, estudiaremos las propiedades semánticas y sintácticas que los adjetivos ordinales del español tienen en función de su disposición lineal con respecto al sustantivo al que acompañan. Las páginas que siguen están organizadas de la siguiente manera. En el apartado $\$ 2$ nos ocuparemos de la interpretación y la distribución de los adjetivos ordinales postnominales e intentaremos demostrar, en concreto, que los ordinales que siguen al nombre pertenecen a la clase de los adjetivos relacionales. El apartado $\$ 3$ está dedicado a la semántica y la combinatoria de los adjetivos ordinales prenominales y en él hablaremos, además, de las propiedades que los ordinales que preceden al nombre tienen en común con adjetivos circunstanciales como anterior, posterior, precedente, siguiente, pasado o próximo, que denotan relaciones de precedencia o sucesión espacio-temporal entre entidades. En el apartado $\$ 4$ completaremos nuestro estudio de los adjetivos ordinales que preceden y siguen al nombre con un breve apunte sobre las propiedades particulares que presentan los dos adjetivos ordinales que marcan los límites inicial y final de una serie ordenada: primero y último.

\section{Los adjetivos ordinales en posición postnominal}

\subsection{Interpretación y distribución de los ordinales postnominales}

Los adjetivos ordinales postnominales simplemente asignan un número al nombre al que acompañan. Esto es, un sintagma nominal como el capitulo primero que he leido, por ejemplo, ha de interpretarse necesariamente como 'el capitulo con el número uno que he leído' y en ningún caso puede interpretarse como 'el capítulo que he leído en primer lugar'.

El hecho de que los ordinales postnominales equivalgan a números explica que determinados sustantivos los admitan con facilidad, mientras que otros, en circunstancias normales, los rechacen. Se combinan, en concreto, sin problemas con un ordinal postpuesto los sustantivos que denotan entidades que por nuestro conocimiento del mundo sabemos que son frecuentemente numeradas y se encuentran asociadas, por tanto, con un determinado número que las caracteriza, tales como los capítulos, los artículos legislativos, los portales, los pisos, las filas, los siglos, etc.:

(8) a. el capitulo primero

b. el artículo tercero

c. el portal quinto

d. el piso sexto 

e. la fila octava
f. el siglo tercero
g. la región militar séptima...

Los sustantivos que denotan entidades que no se suelen numerar no van seguidos, en cambio, de un adjetivo ordinal postnominal. Sabemos, efectivamente, que no es frecuente asignar un número, por ejemplo, a las copas, los árboles, los agujeros, las provincias, las asignaturas o los escalones. Esta es la razón de que las expresiones nominales de (9) con un ordinal postpuesto sean pragmáticamente anómalas:
(9) a. \#la copa tercera/la tercera copa
b. \#el árbol primero / el primer árbol
c. \#el agujero segundo / el segundo agujero
d. Hla provincia cuarta / la cuarta provincia
e. \#la asignatura quinta / la quinta asignatura
f. \#el escalón sexto / el sexto escalón...

Nótese que los sustantivos que admiten fácilmente un ordinal postpuesto no forman una clase semántica, sino que constituyen más bien un grupo definido pragmáticamente por nuestro conocimiento del mundo. Prueba de ello es que las expresiones nominales de (9) con un ordinal postpuesto resultarían aceptables si se modifica el contexto cognitivo y se asigna, por la razón que sea, un número a los sustantivos que las encabezan. Supongamos, por ejemplo, que oímos la secuencia de (9d) en un aula donde el profesor ha numerado las provincias cuyos perfiles se encuentran dibujados en un mapa mudo; en dicho contexto sería perfectamente aceptable decir que la provincia cuarta corresponde, pongamos, a Alicante. También sabemos que en la época del Imperio Romano se daba un número a las provincias, frente a los usos actuales; en este caso resultaría igualmente natural referirse a la provincia cuarta para identificar una determinada provincia.

Datos como los de (10) confirman la idea de que la caracterización del grupo de sustantivos que admiten ordinales postnominales es pragmática:
(10) a. la pista primera (del circo)
b. la linea segunda (del metro)
c. el hoyo tercero (de un campo de golf)
d. la calle cuarta (de una piscina)
e. el paso quinto (de un manual)
f. el libro segundo (de El señor de los anillos)
g. la toma sexta (de una película)...

Los sustantivos de las secuencias de (10) no admiten con facilidad ordinales postpuestos cuando se usan aisladamente, pero se combinan de manera natural con ellos cuando designan entidades que pertenecen a un dominio determinado, donde sí es habitual numerarlas. Así, por ejemplo, es pragmáticamente anómalo asignar números a las pistas, salvo que nos refiramos a las pistas de un circo o a las de un disco compacto. De igual modo, no esperamos que se numeren las líneas, salvo que sean, por ejemplo, las del metro, ni consideramos una actividad normal numerar hoyos, a no ser que se trate de los hoyos de un campo de golf. Algo parecido ocurre con las calles, que no suelen recibir un número en nuestro contexto 
social si no pertenecen a una piscina olímpica, y con los pasos, que no se numeran si no son los que ha de leer en un manual el usuario de algún producto, o también con los libros, que se pueden numerar si forman parte de una serie o una colección, como sucede en la Biblia o en El Señor de los Anillos. Tampoco es normal, en fin, dar un número a las tomas a no ser en el contexto de un rodaje cinematográfico.

Siendo como es una condición pragmática, y no semántica, la que determina la posibilidad de combinar un nombre con un ordinal postpuesto, no debería sorprendernos que los adjetivos de esta clase aparezcan de manera "natural" tan solo con determinados nombres propios: los nombres, en concreto, de monarcas (cfr. (11a)) y de papas (cfr. (11b)).

\section{(11) a. Alfonso décimo \\ b. Pablo sexto \\ c. \#Lucia tercera}

El sintagma nominal Alfonso décimo se usa, así, para identificar dentro de una sucesión temporalmente ordenada de monarcas que comparten el mismo nombre a aquel al que se le asignó en su momento el número diez. Ahora bien, como la aceptabilidad de la secuencia <nombre propiotordinal> está condicionada pragmáticamente, nada impide que alguien pudiera utilizar, con intención irónica o connotaciones humorísticas, una secuencia como la de (1 Ic) para referirse por ejemplo, sin ser ella, claro está, ni reina ni papisa, a la tercera persona llamada Lucía que desempeña un cargo más o menos importante o participa en cualquier sucesión que pueda considerarse una saga, como la formada por las distintas mujeres con dicho nombre que va habiendo en una familia.

Como estamos viendo, cuando se postponen al nombre, los adjetivos ordinales le asignan un número. La prueba más clara de que esto es así es que los sintagmas nominales con ordinales postpuestos y las secuencias en las que un numeral cardinal sigue a un nombre son semánticamente equivalentes e intercambiables entre si ${ }^{7}$ :

(12) a. la fila \{segunda / dos\}

b. el hoyo \{tercero / tres\}

c. el capitulo \{primero / uno\}

d. el piso \{sexto / seis\}

e. Alfonso \{décimo / diez\}...

Este paralelismo entre los ordinales y los cardinales postnominales nos permite dar una explicación para los contrastes de (13):
(13) a. Alfonso \{décimo / *ultimo\}
b. la fila \{segunda / *última\}
c. el hoyo \{tercero / *último\}
d. el piso $\{$ sexto / *último\}...

7 A partir del número diez o doce se prefiere el uso del cardinal, sobre todo en el habla común. Sobre la alternancia en el uso de la lengua entre los ordinales postpuestos y los numerales cardinales véase, v.g., Alcina y Blecua (1975: \$4.6.3), Bello (1847: \$197), RAE (1973: \$2.9.5) y Marcos Marin (1999: 1205). 
No existe ningún número en la serie ilimitada de los números que se corresponda con el ordinal último. De ahí que no pueda aparecer postpuesto al nombre, a no ser con el significado de 'final' (el capítulo último) o de 'principal' (nuestro objetivo último; cfr. §4).

Un ordinal postnominal equivale, por tanto, a todos los efectos a un numeral cardinal también postnominal ${ }^{8}$. En consecuencia, y por sorprendente que parezca, los adjetivos ordinales postnominales no ordenan "necesariamente" una serie. Los numerales cardinales que se colocan detrás de un nombre le atribuyen un determinado rasgo que lo distingue de otras entidades de su misma clase (la propiedad de estar marcado con un número), pero no son ordenadores en sí mismos, aunque puedan serlo de manera subsidiaria habida cuenta de que los números se encuentran ordenados en una serie. Por ello nada impide, por poner un ejemplo, que el capítulo que lleva el número 73 pueda perfectamente ser el primer capítulo del "segundo libro" de Rayuela, del segundo itinerario que Julio Cortázar sugiere al lector para poder leer de manera distinta su novela. Otro tanto ocurre con los adjetivos ordinales postnominales, que tampoco son ordenadores de manera intrínseca. Imaginémonos la siguiente situación a modo de ilustración de esta afirmación. Una calle es tan corta que en ella solo hay un portal y la administración, como a todo portal, le asigna un número. En un contexto como este, el empleo del ordinal prenominal para referirse a dicho portal resulta anómalo (cfr. (14a) $)^{9}$; no hay problema alguno, sin embargo, en usar el ordinal postnominal con este mismo fin (cfr. (14b)):

\section{(14) a. \#Vivo en el primer portal. \\ b. Vivo en el portal primero.}

Los adjetivos ordinales postnominales son, en conclusión, ordinales solo morfofonológicamente. Su semántica, en cambio, es idéntica a la de los numerales cardinales postnominales. Veamos, a continuación, a qué clase de adjetivos pertenecen los ordinales que se sitúan detrás del nombre.

\subsection{Los ordinales postnominales y los adjetivos relacionales}

Los adjetivos relacionales, como marítimo, nacional o lunar en los ejemplos de (15), no expresan, como es sabido, una propiedad, no califican al nombre al que modifican, sino que denotan la relación que este establece con otra entidad, que suele constituir la base morfológica a partir de la cual se forman:

8 Existen varias excepciones a esta generalización:

(i) a. tío \{segundo / \#dos\}, primo \{segundo / \#dos\}

b. sargento \{primero / \#uno \}, cabo \{primero / \#uno

c. causa \{primera/\#uno\}, objetivo \{primero/\#uno\}

En las expresiones lexicalizadas de (ia), el ordinal denota el grado de parentesco que media entre las dos personas involucradas en la relación: un tío segundo es, por ejemplo, 'un tío en segundo grado'. En casos como los de (ib,c), primero se interpreta como 'más importante' o 'principal' (cfr. §4).

9 Un enunciado como el de (14a) solo resulta aceptable en este contexto si el ordinal se coordina con el adjetivo único (Vivo en el primer y único portal de la calle), haciendo explícito que el conjunto ordenado tiene un solo miembro. 
(15) a. puerto maritimo

b. feria nacional

c. paisaje lunar

Los adjetivos de esta clase tienen características propias que los distinguen claramente del resto de los miembros de su categoría gramatical ${ }^{10}$. Revisaremos en esta sección algunas de estas propiedades con el propósito de mostrar que los ordinales postnominales pueden muy bien incluirse dentro del grupo de los adjetivos relacionales ${ }^{11}$.

En primer lugar, dado que los adjetivos relacionales designan relaciones entre entidades, sería esperable que la secuencia formada por un nombre y un adjetivo relacional pudiera ser equivalente a dos sustantivos en aposición. Y esto es, ciertamente, lo que ocurre en algunos casos:

\section{(16) a. estilo \{renacentista / Renacimiento\} \\ b. sillones \{isabelinos / Isabel I\}}

Como decíamos en el subapartado anterior, las expresiones nominales con ordinales postpuestos, por su parte, se pueden sustituir sistemáticamente por una construcción con dos nombres en aposición en la que un numeral cardinal sigue al núcleo nominal:
(17)
a. piso \{sexto / seis\}
b. flla \{segunda / dos\}

En segundo lugar, ni los adjetivos relacionales ni los ordinales postnominales admiten ser graduados $^{12}$ :
(18) a. *puerto maritisimo
b. *paisaje lunarisimo
c. *apitulo primerisimo
d. *hoyo segundisimo

En tercer lugar, y en lo que al orden de palabras respecta, los adjetivos relacionales ocupan una posición de adyacencia estricta al núcleo nominal, de manera que preceden

10 Sobre las propiedades de los adjetivos relacionales véase, v.g., Bosque (1993), Bosque y Picallo (1996), Demonte (1999a) y las referencias alli citadas.

11 Bosque (2002) sugiere que el papel gramatical de los adjetivos ordinales postnominales se puede asimilar al de los adjetivos relacionales. En este subapartado aportaremos pruebas que avalan esta idea.

Bosque (1993) distingue dentro de los adjetivos relacionales entre adjetivos argumentales o temáticos, que funcionan como argumentos del núcleo nominal (la invasión americana, la decisión francesa), y adjetivos clasificadores, que introducen un dominio con respecto al cual el objeto denotado por el nombre es clasificado, restringiéndose de este modo su extensión (un viaje espacial, la industria conservera). Los adjetivos ordinales postnominales no desempeñan, claro está, función semántica alguna y pertenecen, por tanto, al grupo de los adjetivos relacionales clasificadores.

12 Los adjetivos relacionales graduados se convierten, como es sabido, en calificativos, v.g., un paisaje muy lunar, un comportamiento españolísimo. Como veremos en el apartado $\$ 4$, a los ordinales primero y último, cuando aparecen antepuestos, sí se les puede adjuntar en ciertos contextos el sufijo superlativo-isimo. 
obligatoriamente a cualquier tipo de adjetivo calificativo (cfr. (19) $)^{13}$. Los ordinales postnominales, como puede verse en (20), tienen un comportamiento similar:

(19) a. una sierra eléctrica roja ovalada

b. *una sierra roja eléctrica ovalada

c. *una sierra roja ovalada eléctrica

(20) a. un hoyo tercero dificil

b. *un hoyo dificil tercero

c. un capitulo segundo interesante

d. *un capitulo interesante segundo

Los adjetivos relacionales deben aparecer, además, a la derecha del nombre y, cuando se anteponen, si el resultado es gramatical, se recategorizan como calificativos. La anteposición del adjetivo francés en ( $21 \mathrm{~b}$ ), por ejemplo, fuerza la interpretación evaluativa, no relacional, de dicho adjetivo (de ahí que no sea redundante una secuencia como la francesa decisión francesa):

\section{(2I) a. la central lechera / *la lechera central \\ b. la decision francesa / la (muy) francesa decisión}

Los adjetivos ordinales tampoco tienen el mismo valor en posición pre y postnominal. Como ya hemos apuntado, cuando siguen a un nombre, le asignan un número $y$, al igual que los numerales cardinales, no son necesariamente ordenadores. Cuando preceden al nombre, siempre convierten, en cambio, un conjunto de entidades en una serie ordenada según un determinado criterio. Por ello son lícitas combinaciones como las de (22), con un ordinal postpuesto y otro antepuesto:

\section{(22) a. el segundo portal segundo (que hemos limpiado hoy) \\ b. el primer Juan Carlos primero (que reina en España)}

Bosque (2002) menciona otra propiedad de los adjetivos relacionales, que se deriva del hecho de que designen entidades: la coordinación de dos adjetivos relacionales puede interpretarse como un plural. Esta es la razón de que sea gramatical un ejemplo como el de (23a), en el que el plural del sustantivo concuerda con los adjetivos relacionales coordinados. La coordinación de dos adjetivos calificativos, que designan propiedades, no implica, en cambio, pluralidad. De ahí que esté mal formado el sintagma nominal de (23b):

\section{(23) a. los embajadores español y argentino \\ b. *los embajadores alto y bajo}

13 Este hecho, entre otros, ha llevado a pensar a algunos autores que la estructura formada por un nombre y un adjetivo relacional podría formarse en el componente morfológico y ser equivalente a la de un compuesto sintagmático (cfr. Crisma, 1990; Bosque 1993; Zamparelli, 1993). Bosque y Picallo (1996) critican esta idea y proponen que los adjetivos relacionales temáticos se generan en la posición de especificador de SN y que los relacionales clasificadores son categorías máximas que tienen el estatuto de adjuntos. En este trabajo nos limitanos a señalar las propiedades que los ordinales postnominales comparten con los adjetivos relacionales y no nos ocupamos en determinar el nivel gramatical en que ambos se generan. 
Como también observa este lingüista, los ordinales postnominales se comportan como los adjetivos relacionales a este respecto, de modo que el plural del sustantivo concuerda con la pluralidad denotada por los ordinales coordinados:

\section{(24) a. las filas primera y segunda \\ b. los hoyos tercero y cuarto}

Ahora bien, hay dos propiedades de los adjetivos relacionales que, en apariencia, los adjetivos ordinales postnominales no poseen. La primera de ellas es que dos adjetivos relacionales pueden formar parte de un mismo sintagma nominal, posibilidad esta que les está vedada a los ordinales postnominales:

\section{(25) a. la novela policial francesa \\ b. el patrimonio cultural lingüistico \\ c. *la fila primera segunda \\ d. *el hoyo tercero cuarto}

Nótese, no obstante, que la coaparición de dos adjetivos relacionales en una expresión nominal no es posible si ambos hacen referencia a un mismo ámbito semántico y denotan características del nombre al que acompañan, como sucede en una secuencia como *el agua lechosa aceitosa, en la que los dos adjetivos se refieren a la sustancia que contiene la entidad denotada por el núcleo del sintagma nominal ${ }^{14}$. En el caso de la combinación ilícita de dos ordinales postnominales en una misma expresión nominal (*la fila primera segunda, * el hoyo tercero cuarto...) pasa algo parecido: los dos ordinales que caracterizan al nombre hacen referencia a una misma noción semántica (ambos denotan una cifra) y cada uno de ellos le asigna un número distinto, de modo que el resultado es semánticamente anómalo.

Otro aparente contraejemplo a la caracterización de los ordinales postnominales como adjetivos relacionales podría ser el hecho de que los adjetivos relacionales se formen morfológicamente añadiendo un sufijo a un sustantivo claramente reconocible que funciona como una unidad libre en la lengua, mientras que esto no es así en el caso de los ordinales: frente a adjetivos relacionales como lechero, histórico o naval, que conservan en su base los sustantivos leche, historia y nave, los ordinales primero y segundo no guardan relación fonética alguna con los numerales uno y dos y en el resto de los ordinales no se identifica la forma fonética exacta de los cardinales con los que están semánticamente emparentados (tres/tercero, cuatro/cuarto, cinco/quinto, seis/sexto, etc.). Esta situación de falta de transparencia fonética entre el adjetivo derivado y el nombre no es, sin embargo, una excepción dentro de la clase de los adjetivos relacionales: además de los adjetivos ordinales, existen muchos otros adjetivos relacionales que no contienen en su base el sustantivo al que hacen referencia (v.g., guerra/bélico, hermano/fraterno).

En esta sección hemos comprobado que los ordinales postnominales tienen las mismas propiedades que los adjetivos relacionales. Todo parece indicar, por tanto, que los ordinales

14 Dos adjetivos relacionales de semántica similar sí pueden concurrir en una expresión nominal siempre y cuando uno de ellos se subordine semánticamente al otro (cfr. Bosque y Picallo, 1996): en el sintagma bien formado un coma alcohólico metílico, el segundo adjetivo relacional modifica al primero, acotándolo semánticamente (lo que es metílico es el alcohol y no el coma en este ejemplo). 
que se postponen al nombre son, de hecho, adjetivos relacionales. Lo que esto significa, entre otras cosas, es que los ordinales que siguen al nombre no identifican propiamente un lugar en una serie ordenada, sino que denotan la relación que el nombre al que acompañan establece con otra entidad, en este caso, con un número. La interpretación en la que los ordinales postnominales también ordenan una serie es, como ya hemos dicho, un efecto pragmático derivado del hecho de que las entidades con las que expresan una relación, los números, se encuentran ordenadas ellas mismas en una serie.

\section{Los adjetivos ordinales prenominales}

\subsection{Interpretación y distribución de los ordinales prenominales}

Frente a los ordinales postnominales, que funcionan, como acabamos de ver, como los numerales cardinales y no ordenan (necesariamente) un conjunto de entidades, los ordinales que preceden a un nombre son siempre ordenadores y no designan (por regla general) un número ${ }^{15}$. Prueba de ello es un contraste como el de (26):

(26) a. El primer capitulo del libro es el capitulo 73.

b. ${ }^{*}$ El capitulo primero del libro es el capítulo 73.

El escritor argentino Julio Cortázar, como recordábamos en el subapartado $\$ 2.1$, invita al lector a elegir entre las dos posibilidades siguientes: puede empezar su libro Rayuela por el capítulo 1, como es habitual, o por el capítulo 73, lo cual no es tan habitual. En este contexto una oración como la de (26a) cobra pleno sentido. El "primer capítulo de un libro" es el capítulo que precede al resto de los capítulos del libro y no necesariamente, aunque esto sea lo más normal, el capítulo que lleva el número uno. De ahí que pueda estar marcado con otro número, el 73 en este caso. En cambio, la oración de (26b) es semánticamente incongruente: se estaría caracterizando el mismo capítulo con dos números, el 73 y el número uno, que es el que le asigna el ordinal postpuesto.

El distinto significado de los ordinales pre y postnominales queda también patente en ejemplos como los de (27):

(27) a. el primer capitulo que he leido

b. el capitulo primero que he leido

c. la segunda enmienda a un artículo de la Constitución

d. la enmienda segunda a un artículo de la Constitución

Una expresión nominal como la de (27a) admite dos lecturas: el ordinal antepuesto primero puede hacer referencia al orden en que se suceden los capítulos en un libro ('el

\footnotetext{
15 De igual modo que los ordinales postnominales tan solo ordenan en la medida en que forman parte de la serie ordenada de los números, los ordinales prenominales solo pueden denotar un número cuando se asocian con sustantivos que normalmente se numeran, como los capítulos, los portales, los pisos o las filas. El primer capítulo se puede interpretar, por ejemplo, como 'el capítulo con el número uno' porque normalmente el capítulo que precede a los demás en un libro lleva el número uno, pero, como decimos más adelante en el texto, el primer capítulo de un libro podría muy bien llevar un número que no sea el uno, o incluso no llevar ninguno, y lo seguiríamos considerando como tal.
} 
capítulo que precede al resto que he leído') o al orden en que se han leído los capítulos ('el capitulo que he leído en primer lugar'). Este mismo ordinal, si se postpone, no establece en cambio orden alguno en el sintagma nominal de (27b) y simplemente equivale a un número ('el capítulo con el número uno que he leído'). La diferente interpretación de los ejemplos de $(27 \mathrm{c})$ y $(27 \mathrm{~d})$ depende también de la posición del ordinal. En (27c) el ordinal precede al nombre, y se produce una ambigüedad de alcance: podemos entender bien que se nos habla de una enmienda que por segunda vez se presenta a un artículo determinado de la Constitución o bien que es la segunda vez que se enmienda un artículo cualquiera de la Constitución. Por contra, en (27d), al igual que en (27b), el ordinal postnominal tiene una interpretación exclusivamente numérica y este sintagma nominal se interpreta como 'la enmienda con el número dos a un artículo de la Constitución'.

El hecho de que los ordinales postnominales denoten números y los prenominales ordenen una serie nos permite explicar los contrastes de (28), que están en el origen de nuestro interés por la semántica y la sintaxis de los adjetivos ordinales:

\section{(28) a. *el capitulo segundo tercero (que he leido) \\ b. el tercer capitulo segundo (que he leido) \\ c. el tercer segundo capitulo (que he leido)}

La secuencia de (28a) es semánticamente anómala, como ya sabemos (cfr. §2.2), porque una misma entidad queda marcada con dos números diferentes. En la secuencia bien formada de (28b), en cambio, no se asignan dos números a un nombre: solo el ordinal postpuesto denota una cifra; el ordinal antepuesto indica un lugar en una serie de capítulos con el número dos que ha sido ordenada según el criterio del orden en que se han leído, de tal modo que el sintagma nominal que nos sirve de ejemplo se interpreta como 'el capítulo con el número dos que he leído en tercer lugar'. Finalmente, nada impide que dos numerales ordinales puedan aparecer delante del nombre, dado que es semánticamente congruente ordenar por segunda vez, aunque eso sí con un criterio distinto, una entidad que ocupa una posición determinada en una serie ordenada previamente. De este modo, la secuencia con dos ordinales prenominales de $(28 \mathrm{c})$ se interpretaría como 'la tercera versión que he leído del capítulo que ocupa el segundo lugar en la serie ordenada de los capítulos, por ejemplo, de una tesis en proceso de elaboración'.

Nótese que, cuando aparecen dos adjetivos ordinales precediendo a un nombre, el ordinal situado más a la izquierda tiene alcance sobre el ordinal adyacente al núcleo nominal. Es decir, no es posible interpretar nuestro ejemplo como 'la segunda versión que he leído del tercer capítulo de la tesis'. Lo mismo ocurre en una oración como la de (29), en la que las oraciones de relativo hacen explícitos los dos criterios de ordenación que entran ahora en juego:

\section{(29) Este es el [[[primer [[segundo [capitulo] que escribo]] que lees]]]}

En este caso, el capítulo en cuestión ocupa el segundo lugar en una serie si se atiende al criterio del orden en que fueron escritos los capítulos, y de entre los capítulos escritos en segundo lugar se especifica que se trata del primero con respecto al momento en que dichos capítulos son leídos por el interlocutor. Obsérvese que, como indican los corchetes, la oración de relativo más periférica guarda relación con el ordinal situado más a la izquierda 
del nombre, mientras que la oración de relativo más interna está vinculada con el ordinal adyacente al nombre ${ }^{16}$.

Otra propiedad de los ordinales prenominales que los distingue claramente de los postnonimales, y que también se deriva en última instancia del hecho de que ordenen series y no denoten números, es su notable libertad de orden. Como decíamos en el $\$ 2.2$, los ordinales postnominales, que son adjetivos relacionales, aparecen obligatoriamente en una posición adyacente al nombre y preceden, por tanto, a cualquier tipo de adjetivo calificativo (cfr. $(30 \mathrm{a}, \mathrm{b})$ )). Los ordinales prenominales, por su parte, pueden aparecer a la derecha o a la izquierda de un adjetivo calificativo también prenominal, ya que es perfectamente posible tanto calificar una entidad previamente ordenada como ordenar entidades calificadas (cfr. $(30 \mathrm{c}, \mathrm{d})$ ).

\section{(30) a. un capitulo primero extenso \\ b. *un capítulo extenso primero \\ c. un extenso primer capitulo \\ d. un primer extenso capitulo}

Los ordinales prenominales concurren en cualquier orden, de hecho, con las cuatro clases de adjetivos prenominales que Demonte (1999b) distingue — los adjetivos calificativos no restrictivos, los adjetivos circunstanciales, los adjetivos epistémicos modales y los adjetivos intensionalmente orientados $-{ }^{17}$, dando lugar, claro está, a interpretaciones diferentes dependiendo de las relaciones de ámbito que establezcan entre si el ordinal y el adjetivo con el que se combina.

Pueden preceder o seguir, en primer lugar, a los ordinales prenominales, como acabamos de decir, los adjetivos calificativos no restrictivos, que destacan un rasgo del objeto denotado por la entidad de la que se predican. En (30c), por ejemplo, se selecciona el primer capítulo dentro de una serie y se destaca su extensión, pero no tiene por qué haber más capítulos con esta propiedad en dicha serie. En (30d) tenemos, en cambio, una serie ordenada de capítulos de los que se destaca la propiedad de que son extensos y escogemos el primero de dicha serie conforme a un determinado criterio de ordenación ${ }^{18}$.

16 El número de ordinales prenominales y de cláusulas de relativo con ellos asociadas no está restringido gramaticalmente a dos. Una oración como Este es el [[[[primer [[[segundo [[tercer [libro] que escribo]] que lees]]] que me publican]]]] es gramatical, pero resulta inaceptable por lo dificil que resulta procesarla.

17 Sobre la clasificación de los adjetivos prenominales véase también Valois (1991), Cinque (1994) y Demonte (1999a). Pueden encontrarse en la bibliografia propuestas de muy distinto signo sobre la posición estructural en la que se generan los adjetivos. Algunos autores los analizan de manera uniforme y sostienen que todos ellos son o bien especificadores de una categoría funcional (Crisma, 1990; Cinque, 1994) o bien adjuntos (Svenonius, 1994; Bouchard, 1998). Otros autores consideran que los adjetivos no constituyen una clase estructuralmente uniforme (cfr., v.g., Bernstein, 1993; Martín, 1995; Sánchez, 1996; Demonte 1999b). Recientemente, Bouchard (2002) adopta una versión del modelo de las estructuras de frase escuetas de Chomsky (1995) en la que no distingue entre sustitución y adjunción y supone que la disposición lineal de los adjetivos en el SN es una proyección directa de sus propiedades semánticas, que son las que activan la operación de ensamble con el nombre o con una unidad sintagmática mayor ya formada. Esta propuesta, que intenta dar cuenta, entre otras cosas, de la notable movilidad de los adjetivos con respecto al nombre y entre sí sin tener que recurrir a proyecciones funcionales u operaciones sintáticas ad hoc, podría muy bien valer también para los numerales ordinales.

18 Alarcos (1994: \$163) ofrece datos que también ilustran esta alternancia de orden entre los ordinales y los calificativos prenominales:

(i) a. los cálidos primeros días de mayo

b. los primeros cálidos días de mayo

c. su grata quinta visita

d. su quinta grata visita 
Los adjetivos circunstanciales, como antiguo, cercano o frecuente, que denotan parámetros temporales, espaciales o aspectuales asociados con el nombre, también preceden o siguen a los ordinales prenominales. Supongamos, a modo de ejemplo, que un país, por la razón que sea, tiene varias capitales. En el ejemplo de (31a), sobre un conjunto ordenado de capitales, se selecciona la primera y se dice de ella que antiguamente fue la primera capital. Usaríamos, en cambio, la secuencia de (31b), en la que el ordinal aparece delante del adjetivo circunstancial y tiene, por tanto, alcance sobre él, para seleccionar, dentro de un conjunto ordenado formado por las capitales anteriores del país, a la primera de dicha serie:

\section{(31) a. la antigua primera capital \\ b. la primera antigua capital}

Los adjetivos modales, que son aquellos, como presunto, supuesto o probable, que califican la actitud del hablante ante lo apropiado de la designación empleada para un referente determinado, alternan igualmente su posición con los adjetivos ordinales prenominales:

\section{(32) a. el presunto primer asesino \\ b. el primer presunto asesino}

La expresión nominal de (32a), con el ordinal adyacente al nombre, se emplearía en una situación en la que, dentro de un grupo de asesinos (por ejemplo, varias personas que intervinieron consecutivamente hasta matar a una persona), se duda que la persona que intervino en primer lugar sea realmente un asesino. En (32b), el ordinal precede al adjetivo intensional y el significado cambia de nuevo: de un conjunto de personas de las que se supone que puedan ser asesinos identificamos a aquel que ocupa el primer lugar dentro de una serie ordenada conforme a un criterio determinado.

Finalmente, como los adjetivos prenominales de las otras tres clases, los adjetivos intensionales como verdadero, rotundo o completo, que indican el estatuto que tiene un referente dentro de la clase definida por las propiedades denotadas por el sustantivo, también se pueden colocar delante o detrás de un ordinal prenominal, con las esperables diferencias de ámbito entre el adjetivo y el ordinal dependiendo de cómo se dispongan linealmente ${ }^{19}$ :

\section{(33) a. mi verdadero primer amor \\ b. mi primer verdadero amor \\ c. su rotundo primer fracaso \\ d. su primer rotundo fracaso}

La misma libertad de orden que los ordinales prenominales manifiestan cuando se combinan con un adjetivo se observa también en las secuencias prenominales formadas por un ordinal y un numeral cardinal:

(34) a. los dos primeros concursantes

b. los primeros dos concursantes

19 Algunos adjetivos prenominales que normalmente se incluyen en la clase de los intensionales, como simple, mero o puro, difícilmente se combinan con ningún otro tipo de adjetivo y tampoco lo hacen con los ordinales prenominales. En consecuencia, expresiones nominales como la pura primera ley o la primera pura ley solo están bien formadas si se interpreta el adjetivo puro como un epíteto. 
Los sintagmas nominales de (34a) y (34b) están ambos bien formados, pero, al igual que ocurría en los casos en que aparecían juntos en una expresión nominal un ordinal prenominal y un adjetivo también prenominal, su significado varía dependiendo del orden de palabras, que en última instancia es un reflejo de las relaciones estructurales jerárquicas. Así, el ejemplo de (34a) se usaría preferentemente en un contexto en el que hubiera una única serie de concursantes y seleccionáramos de entre ellos a los dos que se encuentran al principio de dicha serie, es decir, al primer concursante y al segundo ${ }^{20}$. En el ejemplo de (34b), en cambio, se presupone que los concursantes han sido previamente agrupados por pares (como sucede, por ejemplo, en un campeonato de mus, en el que participan necesariamente equipos de dos jugadores) y, al formar una serie ordenada con los concursantes así distribuidos, escogemos el primer par. Esta distinta interpretación se sigue de forma natural, como hemos dicho más arriba, de las distintas relaciones de alcance semántico que esperamos que el numeral ordinal y el numeral cardinal establezcan el uno con el otro dependiendo de la posición sintáctica que ocupan: en (34a) el cardinal precede al ordinal, se sitúa, por tanto, en una posición más alta en la estructura y tiene alcance sobre él; en (34b) el orden se invierte y es el ordinal el que tiene ahora alcance sobre el numeral cardinal.

En esta sección hemos caracterizado los adjetivos ordinales prenominales como ordenadores inherentes no numéricos que siempre proyectan un conjunto de entidades en una serie ordenada y hemos analizado su peculiar combinatoria con los adjetivos y los numerales cardinales que preceden al nombre. En el siguiente subapartado intentaremos mostrar que los ordinales prenominales pertenecen a la clase, ya mencionada, de los adjetivos circunstanciales.

\subsection{Los ordinales prenominales y los adjetivos circunstanciales ${ }^{21}$}

El significado de los ordinales prenominales es claramente distinto del de los adjetivos antepuestos calificativos, intensionales y modales: un ordinal prenominal indica el lugar que ocupa el nombre al que acompaña en una serie ordenada y no lo califica, por tanto, ni modifica tampoco su significado o intensión, ni refleja la actitud del hablante ante la adecuación del término empleado para nombrar a un referente. Su semántica se aproxima, en cambio, a la de los adjetivos circunstanciales. Como decíamos, los adjetivos circunstanciales expresan nociones relacionadas con la temporalidad (antiguo, futuro), la aspectualidad (frecuente, constante) o la localización de una entidad en el espacio (cercano, lejano $)^{22}$. Los ordinales prenominales también expresan nociones espacio-temporales en tanto que convierten un

20 Hay otra interpretación posible del ejemplo de (34a). Supongamos que, a partir del conjunto total de concursantes, se forman dos grupos y cada uno de ellos es ordenado por separado. En tal caso, esta secuencia podría referirse a una situación en la que se selecciona a los dos concursantes, uno de cada grupo, que ocupan el primer lugar de cada una de las series.

21 Los ordinales prenominales, a diferencia de los numerales cardinales, son siempre adjetivos y nunca funcionan como determinantes, dado que no legitiman una expresión nominal en posición de argumento, como la de sujeto oracional:

(i) a. (Los) dos estudiantes han aprobado.

b. Los \{primeros/aplicados\} estudiantes han aprobado.

c. * $\quad$ Primeros/Aplicados $\}$ estudiantes han aprobado.

22 Sobre las propiedades de los adjetivos circunstanciales (también llamados adjetivos eventivos o adjetivos situacionales) véase Demonte (1999a), (1999b) y las referencias allí citadas. 
conjunto en una serie cuyos miembros están dispuestos necesariamente uno detrás de otro. Del hecho mismo de que exista una serie ordenada se sigue, así, que modifiquen a un nombre indicando el lugar que este ocupa dentro de una sucesión temporal (como el orden, por ejemplo, en que han nacido los hijos de una pareja) o espacial (como la disposición de los capítulos de un libro o los peldaños de una escalera).

Los ordinales prenominales presentan semejanzas sustanciales, en concreto, con un grupo determinado de adjetivos circunstanciales, el grupo formado por adjetivos como siguiente, precedente, posterior, anterior, próximo o pasado, que denotan relaciones de precedencia o sucesión entre entidades de la misma clase en una secuencia temporal o espacial $^{23}$. Veamos algunas de ellas.

En primer lugar, como acabamos de señalar, los adjetivos ordinales prenominales también nos informan, si bien de manera derivada, acerca de la posición que ocupa una entidad en una secuencia espacio-temporal. En segundo lugar, tanto los ordinales prenominales como los adjetivos circunstanciales de esta clase modifican a nombres discontinuos (cfr. $(35 \mathrm{a}, \mathrm{b})$ ) y denotan intrínsecamente relaciones (cfr. (35c)):

\section{(35) a. la \{tercera / siguiente\} pregunta \\ b. Hla \{primera/anterior\} pereza \\ c. *La pregunta es \{tercera / siguiente\}.}

Además, cuando se sitúan delante del nombre, los adjetivos circunstanciales de esta clase, al igual que los ordinales prenominales (cfr. \$3.1), preceden o siguen tanto a los adjetivos calificativos, modales e intensionales como a los numerales cardinales, obteniéndose de nuevo interpretaciones distintas en función de cuál sea el orden resultante ${ }^{24}$.

(36) a. la \{́próxima vieja / vieja próxima\} estación

b. la \{posterior probable / probable posterior\} discusión

c. la \{siguiente verdadera verdadera siguiente\} razón

d. los \{anteriores dos / dos anteriores\} capitulos

La buena formación, por último, de oraciones como las de (37), en las que se combinan en una misma serie sintagmas nominales que contienen ordinales prenominales y sintagmas nominales con adjetivos circunstanciales, refuerza la idea de que unos y otros forman parte del mismo grupo de adjetivos:

(37) a. Alonso ganó la primera carrera y la segunda; la siguiente la perdió.

b. De la tetralogía de Wagner me gusta la segunda ópera; la anterior me aburre.

23 Schnedecker $(2000 ; 2001)$ apunta de pasada esta idea para el francés. En esta sección analizamos de manera más sistemática las semejanzas y las diferencias que existen entre los ordinales prenominales y los adjetivos circunstanciales de esta clase, a la que también pertenecen adjetivos como inicial, final o sucesivo. La mayor parte de estos adjetivos tiene valor anafórico y establece relaciones tanto temporales como espaciales. Pasado y próximo, sin embargo, son adjetivos deícticos y el primero de ellos solo se emplea en secuencias temporales (cfr. Demonte, 1999a; Berthonneau, 2002). El estudio detallado de la semántica y la sintaxis de los distintos miembros de este grupo de adjetivos circunstanciales queda fuera del alcance de este trabajo.

24 Los adjetivos circunstanciales de esta clase, al igual que otros adjetivos circunstanciales (cfr. $\$ 3.1$ ), se combinan también con los ordinales prenominales, pero en este caso el único orden posible es aquel en que el adjetivo circunstancial precede al ordinal: el \{siguiente primer / *primer siguiente\} capitulo. 
Existen, no obstante, dos diferencias importantes entre los ordinales prenominales y los adjetivos circunstanciales de la clase de siguiente o anterior. La primera de ellas es semántica. Adjetivos como siguiente o anterior denotan únicamente relaciones espaciotemporales de precedencia o sucesión entre entidades. Los ordinales prenominales, por su parte, también hacen referencia a la relación que existe entre entidades de una misma clase en una secuencia lineal (temporal o espacial), pero son, por encima de todo, ordenadores: convierten un conjunto en una serie ordenada. Como decíamos en la introducción, para poder proyectar un conjunto en una serie ordenada, hay que seleccionar o extraer previamente uno a uno los miembros del conjunto, esto es, se debe hacer particiones sucesivas en el conjunto de referencia. Schnedecker (2000) sugiere que esta operación de partición en un conjunto preexistente de entidades de la misma clase es lo que más claramente distingue a los ordinales prenominales de adjetivos como siguiente o anterior, cuya naturaleza sería exclusivamente temporal o espacial ${ }^{25}$. Compartimos esta idea, que nos permite dar cuenta además del hecho de que solo los ordinales prenominales puedan ser la cabeza de una construcción partitiva:

(38) a. el \{primero / *siguiente\} de los tres capitulos del libro de Cortázar

b. La \{primera / *anterior\} de las cuatro preguntas que me hicieron

La segunda diferencia entre los ordinales y los adjetivos circunstanciales de la clase de siguiente o anterior es sintáctica. Los adjetivos ordinales, como sabemos, tienen distinta denotación en posición pre y postnominal: cuando preceden al nombre, identifican el lugar que este ocupa en una serie ordenada; cuando lo siguen, le asignan un número. Como se ilustra en (39), los adjetivos circunstanciales de la clase que nos ocupa se sitúan por lo general, en cambio, delante o detrás del nombre sin que cambie su significado ${ }^{26}$ :

\section{(39) a. el siguiente capitulo / el capitulo siguiente \\ b. la próxima semana / la semana próxima \\ c. el pasado lunes / el lunes pasado...}

En esta sección hemos querido mostrar los puntos de contacto que existen entre los ordinales prenominales y los adjetivos circunstanciales que denotan relaciones espacio-temporales entre entidades de la misma clase, como siguiente, anterior, posterior, precedente, pasado o próximo ${ }^{27}$. Pondremos punto final a este trabajo con un breve comentario sobre las propiedades idiosincrásicas de los ordinales primero y último.

25 Como nos indica Cristina Sánchez (c.p.), una prueba de que los adjetivos como siguiente o anterior no son partitivos o seriales es que cuando decimos expresiones del tipo de como ilustra el siguiente ejemplo no necesitamos ejemplos previos; se trata de un ejemplo que sigue al texto.

26 Sobre el orden de los adjetivos circunstanciales con respecto al nombre véase Demonte (1999a), (1999b).

27 Brucart y Rigau (2002: \$8.2.1.4) caracterizan los numerales ordinales como "adjetivos determinativos" "porque son entidades que pueden ser interpretadas por medio de mecanismos de deixis o de anáfora". Resulta dificil, sin embargo, definir con precisión esta supuesta clase de adjetivos y decídir qué adjetivos pertenecen a ella y cuáles no: nótese, por ejemplo, que la razón que aducen estos autores para incluir los ordinales en la clase de los adjetivos determinativos valdría también para los adjetivos circunstanciales que nos han ocupado en esta sección, dado que tienen igualmente valor anafórico o déíctico. 


\section{Un apunte sobre primero y ültimo}

Primero y último presentan la particularidad de que establecen el principio y el fin de una serie ordenada. Este hecho explica las propiedades que los distinguen del resto de los adjetivos ordinales ${ }^{28}$.

Último cierra una serie y es por ello el único ordinal que puede coordinarse con otro ordinal, siguiéndolo y modificando a un nombre en singular:

\section{(40) a. el tercer y último capitulo del libro \\ b. *el último y tercer capítulo del libro \\ c. *el tercer y cuarto capítulo del libro}

Nada impide además que podamos tomar como límite inicial o final de una serie un intervalo en lugar de un único punto. De ahí que en un ejemplo como el de (41a) el ordinal primeros pueda hacer referencia tanto al primer clasificado de dos series distintas de clasificados como al primer y al segundo clasificado de una misma serie. En (42b), en cambio, el ordinal segundos identifica a las personas que ocupan el segundo lugar en dos clasificaciones distintas (o a las personas que ocupan, empatadas, el segundo lugar en una clasificación), pero no puede referirse, digamos, al segundo y al tercer clasificado en una misma clasificación porque este ordinal, a diferencia de primero o último, nunca identifica un intervalo compuesto por varios lugares sucesivos de la serie ${ }^{29}$.

\section{(4I) a. los dos primeros clasificados \\ b. los dos segundos clasificados}

El carácter valorativo que primero y último adquieren en ocasiones, y que se manifiesta en que se les pueda adjuntar el sufijo superlativo -ísimo, también tiene que ver, a fin de cuentas, con que se sitúen en el extremo de una serie ordenada y puedan así expresar cualidades que se asocian pragmáticamente al hecho de ser el elemento que abre o cierra una serie ${ }^{30}$ :

(42) a. de \{primerisima / *segundisima\} fila

b. de \{primerisima / *segundisima\} categoría

c. por \{ultimisima /*tercerisima\} vez

d. en \{ultimisimo /*tercerismo\} lugar

28 Sobre el comportamiento de premier y dernier en francés véase Schnedecker $(2001,2002)$.

29 Como nos hace ver Cristina Sánchez (c.p.), una prueba clara de que primero y último pueden referirse a intervalos son expresiones como los \{primeros/últimos\} dias del mes o Estamos a \{primeros/íltimos\} de mes, ejemplos en los que estos ordinales no son realmente tales y se oponen a mediados, que no es un ordinal.

30 La etimología de primero y último es también peculiar: ni primero ni íltimo se han formado a partir de un numeral cardinal. Otra diferencia entre los ordinales que abren y cierran una serie y el resto es que solo los primeros dan lugar en español actual a adverbios en -mente: primeramente 'en primer lugar, antes de nada', últimamente 'recientemente' (en etapas anteriores de la lengua se usaba segundamente con los significados de 'en segundo lugar' - 'a continuación' y adverbios como terceramente, cuartamente, etc. funcionaban como marcadores discursivos al menos hasta mediados del siglo XV, como se puede comprobar, por ejemplo, en la traducción y glosas de $L a$ Eneida de Dn. Enrique de Villena, fechada en 1427-28). 
Además de estas tres, existen otras propiedades particulares de primero y último que se siguen específicamente del hecho de que estos adjetivos puedan marcar también los límites superior e inferior de una escala jerarquizada. Este carácter de designadores de límites en una escala les da una relevancia pragmática de la que pueden derivarse otros significados. Primero, por ejemplo, equivale semánticamente al adjetivo principal cuando forma expresiones lexicalizadas con nombres que denotan funciones u oficios, como sargento primero, cabo primero, primera dama, primer actor, primer espada o primer tenor. Nótese que se trata de casos en los que se identifica la entidad de mayor rango de manera absoluta, sin que haya que presuponer la existencia de una jerarquía ordenada: en tales casos, primero, como el adjetivo principal, no es un ordinal en sentido estricto.

Tanto primero como último tienen también el significado de 'principal o más importante' cuando se anteponen o se postponen a nombres abstractos como causa, razón, motivación, objetivo, propósito o finalidad. En secuencias como las de (43), por ejemplo, primero y último tampoco son ordinales en sentido estricto, y se comportan como un adjetivo calificativo $^{3 !}$ :

\section{(43) a. el \{primer / principal\} objetivo del gobierno \\ b. la \{primera / principal\} causa de mortalidad infantil \\ c. la finalidad fúltima / más importante\} de estas medidas \\ d. la causa \{última / más importante\} de lo que ha sucedido}

El hecho de que identifiquen la entidad que se encuentra en el extremo superior o inferior de una escala hace posible, finalmente, que primero y último, al igual que el adjetivo principal, puedan desempeñar el papel de propiedad graduada en una construcción superlativa analítica:

(44) a. el \{primer / principal\} problema de todos

b. el problema más importante de todos

c. el último alumno de su clase

d. el peor alumno de su clase

Los adjetivos principal, primero y último no tienen valor elativo o superlativo de manera intrínseca, pero lo adquieren en virtud de su capacidad para indicar que una entidad ocupa la posición más destacada en la parte superior o inferior de una escala.

\section{Conclusiones}

En este artículo hemos estudiado las propiedades semánticas y el comportamiento sintáctico de los adjetivos ordinales del español en posición pre y postnominal. Hemos intentado demostrar, en primer lugar, que los ordinales postnominales son adjetivos relacionales que asignan un número al sustantivo al que modifican y no ordenan necesariamente una serie, aunque puedan hacerlo de manera derivada, dado que los números están ordenados 
ellos mismos en una serie. En segundo lugar, hemos llegado a la conclusión de que los adjetivos ordinales que preceden al nombre siempre convierten un conjunto de entidades en una serie ordenada y pertenecen al grupo de los adjetivos circunstanciales, como siguiente, anterior, próximo o pasado, que denotan relaciones de precedencia o sucesión entre entidades de la misma clase en una secuencia temporal o espacial. Y hemos revisado también, por último, las propiedades de los ordinales primero y último, unas propiedades particulares que se derivan, en última instancia, del hecho de que estos adjetivos marcan el comienzo y el final de una secuencia espacio-temporal o los extremos superior e inferior de una escala jerarquizada.

\section{Referencias bibliográficas}

Alarcos, E. (1994): Granática de la lengua española. Madrid, Espasa Calpe. Alcina Franch, J. y J. M. Blecua (1975): Gramática española. Barcelona, Ariel. Bello, A. (1847): Gramática de la lengua española. [Edición de R. Trujillo, Tenerife, 1981]. Bernstein, J. (1993): Topics in the Syntax of Nominal Structure across Romance. Tesis doctoral inédita. CUNY, Nueva York.

Berthonneau, A-M. (2002): “Prochain/Dernier et compagnie. Les adjectifs 'déictiques' à l'épreuve de l'espace ou comment circuler dans le temps, l'espace, le texte", Langue Française, 136, págs. 104-125.

Bosque, I. (1993): "Sobre las diferencias entre los adjetivos relacionales y los calificativos", Revista Argentina de Lingüística, 9, págs. 9-48.

Bosque, I. (2002): “¿Singular+singular = plural? Aspectos de la concordancia de número en las construcciones coordinadas". Manuscrito inédito, Universidad Complutense de Madrid.

Bosque, I. y C. Picallo (1996): "Postnominal Adjectives in Spanish", Journal of Linguistics, 32, págs. 349-385.

Bosque, I. y V. Demonte (dirs.) (1999): Gramática descriptiva de la lengua española. Madrid, Espasa Calpe.

Bouchard, D. (1998): "The Distribution and Interpretation of Adjectives in French: A Consequence of Bare Phrase Structure", Probus, 10, págs. 139-183.

Bouchard, D. (2002): Adjectives, Number and Interfaces. Why Languages Vary. Londres, Elsevier.

Brucart, J. Ma y G. Rigau (2002): "La quantificació". En Solà, J. et alii (eds.): Gramàtica del català contemporani, vol. 2. Barcelona, Empúries, págs. 1517-1589.

Chomsky, N. (1995): The Minimalist Program. Cambridge (Mass.), The MIT Press.

Cinque, G. (1994): "On Evidence for Partial N-Movement in the Romance DP". En Cinque, G. et alii (eds.): Paths Towards Universal Grammar. Georgetown, Georgetown University Press, págs. $85-110$.

Crisma, P. (1990): Functional Categories inside the NP: A Study on the Distribution of Nominal Modifiers. Tesis doctoral inédita, Universidad de Venecia.

Demonte, V. (1999a): "El adjetivo: clases y usos. La posición del adjetivo en el sintagma nominal". En Bosque, I. y V. Demonte (dirs.), vol. I, págs. 129-212.

Demonte, V. (1999b): "A Minimal Account of Spanish Adjective Position and Interpretation". En Franco, J., A. Landa y J. Martín (eds.): Grammatical Analyses in Basque and Romance Linguistics. Amsterdam, John Benjamins, págs. 45-75.

Fernández Ramírez, S. (1951): Gramática española. [Segunda edición en cinco volúmenes, Madrid, Arco Libros, 1986].

Marcos Marín, F. (1999): "Los cuantificadores: Los numerales". En Bosque, 1. y V. Demonte (dirs.), vol. I, págs. 1189-1208. 
Martín, J. (1995): On the Syntactic Structure of Spanish Noun Phrases. Tesis doctoral inédita, University of Southern California, Los Ángeles.

Martín Zorraquino, Ma A. y J. Portolés Lázaro (1999): "Los marcadores del discurso". En Bosque, I. y V. Demonte (dirs.), vol. III, págs. 4051-4213.

Portolés, J. (1998): Marcadores del discurso. Barcelona, Ariel.

Real Academia Española (1973): Esbozo de una nueva gramática de la lengua española. Madrid, Espasa Calpe.

Sánchez, L. (1996): Syntactic Structures in Nominals: A Comparative Study of Spanish and Southern Quechua. Tesis doctoral inédita, University of Southern California, Los Ángeles.

Schnedecker, C. (2000): "Ordre des ordinaux pronominaux", Travaux de linguistique, 41.2, págs. 7-34.

Schnedecker, C. (2001): "Premier, second et dernier: des ordinaux peu ordinaires", Le Français Moderne, $\mathrm{LXIX} / 1$, págs. 21-38.

Schnedecker, C. (2002): "Premier, principal, primordial: des adjectifs qui sortent du rang?", Langue Française, 136, págs. 89-103.

Svenonius, P. (1994): "The Structural Location of the Attributive Adjective". En Farkas, D. y P. Spaelti (eds.): Proceedings of the Twelfth West Coast Conference on Formal Linguistics (WCCFL), Stanford, págs. 439-455.

Valois, D. (1991): The Internal Syntax of DP. Tesis doctoral inédita, Universidad de California, Los Ángeles.

Zamparelli, R. (1993): "Prenominal Modifiers, Degree Phrases and the Structure of AP", University of Venice Working Papers in Linguistics, 3, págs. 138-161. 